\title{
Attendance at an asthma clinic did not reduce asthma morbidity more than did standard medical treatment
}

Heard AR, Richards IJ, Alpers JH, et al. Randomised controlled trial of general practice based asthma clinics. Med J Aust 1999 Jul 19;171:68-71.

QUESTION: In patients with asthma, does attendance at a general practice asthma clinic reduce asthma morbidity more than does standard medical treatment?

\section{Design}

6 month randomised \{allocation concealed*\}, $\uparrow$ unblinded,* controlled trial.

\section{Setting}

8 general practices in South Australia.

\section{Patients}

195 patients who were 5 to 64 years of age (mean age 26 y, $55 \%$ women) and had asthma. Follow up was $98 \%$.

\section{Intervention}

Patients were allocated to an asthma clinic group $(\mathrm{n}=98)$ or a standard treatment group $(\mathrm{n}=97)$. Asthma clinics operated once per week for a 3 hour session. Registered nurses with extensive respiratory care experience educated patients in asthma management strategies, including a written asthma management plan; spirometry; and use of peak flow meters, inhalers, and asthma diary cards. Asthma clinic group patients were asked to attend 3 sessions.

\section{Main outcome measures}

Days missed from work or school; use of an action plan; medication use; current smoking; level of morning or nocturnal asthma symptoms; and number of hospitalisations, emergency visits, and home visits by general practitioners.

\section{Main results}

Of the 98 patients allocated to the asthma clinic group, 67 attended 3 sessions, 17 attended 1 or 2 sessions, 13 attended no sessions, and 1 patient withdrew. Analysis was by intention to treat. The study had $80 \%$ power to detect a $50 \%$ reduction in the proportion of patients reporting $\geq 1$ day lost from work. At 6 months, patients in the asthma clinic group were more likely than patients in the standard treatment group to own a peak flow meter and less likely to be awakened at night because of asthma (table). A trend existed for more patients in the asthma clinic group to begin or recommence smoking (table). The groups did not differ for any other outcomes.

\section{Conclusions}

Patients with asthma who attended a general practice asthma clinic were more likely to own a peak flow meter and less likely to wake at night because of asthma than those receiving standard medical treatment, but they did not differ for any other measures of asthma morbidity.

*See glossary. $\dagger$ Information provided by author.

\section{COMMENTARY}

Advances in medicine have led to improved outcomes for many diseases, but the burden of suffering from asthma is increasing. Current efforts to reduce the morbidity from asthma focus on better delivery of care and patient education. Such interventions as asthma clinics and home visits are now common.

Heard and colleagues have shown that an asthma clinic in addition to routine physician care has little effect. They point out, however, the limitations of the study. First, control and intervention group patients were often seen by the same physician who, aware that his or her practice behaviour was under scrutiny, may have provided more conscientious care than usual. Second, Heard and colleagues studied mostly patients with less severe asthma, as reflected by the low hospitalisation rate in both groups. Third, the study was small, and many patients did not complete the asthma clinic intervention. Given these shortcomings, it is impossible to conclude that asthma clinics in general are not useful. Other interventions, including home visits and community outreach programs, have substantially improved ${ }^{12}$ patient education and such cost sensitive outcomes as emergency department visits. Heard and colleagues show that general practitioners, under the right circumstances and with some incentive, are able to provide quality asthma care and education. The best targets for new asthma programs are perhaps the physicians themselves.

Goutham Rao, MD University of Pittsburgh Medical Center Pittsburgh, Pennsylvania, USA

1 Dickinson J, Hutton S, Atkin A, et al. Reducing asthma morbidity in the community: the effect of a targeted nurse-run asthma clinic in an English general practice. Respir Med 1997;91:634-40.

2 Greineder DK, Loane KC, Parks P. Reduction in resource utilization by an asthma outreach program. Arch Pediatr Adolesc Med 1995;149:415-20.

Asthma clinic $v$ standard medical treatment for asthma morbidity at 6 months

\begin{tabular}{|c|c|c|c|c|}
\hline Outcomes & $\begin{array}{l}\text { Asthma } \\
\text { clinic }\end{array}$ & $\begin{array}{l}\text { Standard } \\
\text { care }\end{array}$ & $\begin{array}{l}\mathrm{RBI} \\
(95 \% \mathrm{Cl})\end{array}$ & $\begin{array}{l}\text { NNT } \\
\text { (Cl) }\end{array}$ \\
\hline \multirow[t]{2}{*}{ Owning a peak flow meter } & $73 \%$ & $56 \%$ & $\begin{array}{c}30 \% \\
\text { (5 to } 62)\end{array}$ & $\begin{array}{l}6 \\
(3 \text { to } 31)\end{array}$ \\
\hline & & & \multicolumn{2}{|l|}{$\operatorname{RRR}(\mathrm{Cl})$} \\
\hline \multirow[t]{2}{*}{ Waking at night because of asthma } & $7.0 \%$ & $20 \%$ & $\begin{array}{l}64 \% \\
(21 \text { to } 84)\end{array}$ & $\begin{array}{l}8 \\
\text { (4 to } 29)\end{array}$ \\
\hline & & & $\mathrm{RRI}(\mathrm{Cl})$ & NNH (Cl) \\
\hline Currently smoking & $15 \%$ & $7 \%$ & $\begin{array}{l}108 \% \\
(-8.5 \text { to } 378)\end{array}$ & $\begin{array}{l}\text { Not } \\
\text { significant }\end{array}$ \\
\hline
\end{tabular}

†Abbreviations defined in glossary; RBI, RRR, RRI, NNT, NNH, and Cl calculated from data in article. 